\title{
Structural and DFT Studies on Molecular Structure of Pyridino-1-4-n-cyclohexa-1,3-diene and 2-Methoxycyclohexa-1,3-diene Irontricarbonyl Complexes
}

\author{
Olawale Folorunso Akinyele ${ }^{1,}$, , Timothy Isioma Odiaka ${ }^{2}$, Isiah Ajibade Adejoro ${ }^{2}$ \\ ${ }^{1}$ Department of Chemistry, Obafemi Awolowo University, Ile-Ife, Nigeria \\ ${ }^{2}$ Department of Chemistry, University of Ibadan, Ibadan, Nigeria
}

Email address:

ofakins@yahoo.com (O. F. Akinyele), ofakinyele@oauife.edu.ng (O. F. Akinyele)

${ }^{*}$ Corresponding author

To cite this article:

Olawale Folorunso Akinyele, Timothy Isioma Odiaka, Isiah Ajibade Adejoro. Structural and DFT Studies on Molecular Structure of Pyridino-1-4- $\eta$-cyclohexa-1, 3-diene and 2-Methoxycyclohexa-1, 3-diene Irontricarbonyl Complexes. American Journal of Physical Chemistry. Vol. 8, No. 2, 2019, pp. 41-49. doi: 10.11648/j.ajpc.20190802.12

Received: April 25, 2019; Accepted: June 24, 2019; Published: September 25, 2019

\begin{abstract}
We report a molecular simulation of Pyridino-1-4-n-cyclohexa-1,3-diene and 2-methoxycyclohexa-1,3-diene irontricarbonyl complexes. In this work we employed the Density Functional Theory (DFT) in our calculations to predict the dipole moment, spectra, HOMO-LUMO energies, and chemical reactivity parameters including chemical potential, global chemical hardness, electrophilicity index and polarizability revealing that the complexes are highly reactive. The calculated values were compared with the available experimental values for these compounds as a means of validation. A very good agreement has been obtained between B3LYP theoretical results and the experimental results. We also calculated the excitation wavelength with time-dependent density functional theory and observed a mixture of singlet-singlet and singlet to triplet excitation energies.
\end{abstract}

Keywords: Density Functional Theory, HOMO-LUMO Energy Band Gap, ${ }^{1} \mathrm{H},{ }^{13} \mathrm{C}$ NMR Spectra, Chemical Potential, Electrophilicity

\section{Introduction}

The synthesis of novel compounds is of prime importance. Qualitative Structure Activity Relationship (QSAR) is an important predictive tool for a preliminary evaluation of the activity of chemical compounds, this can be achieved by using computer-aided models. The Hohenberg and Kohn Sham theorem based Density Functional Theorem (DFT) provide a major boost to the computational chemists in the design and the study of the properties of molecular structures [1-3]. DFT methods are in general capable of generating a variety of isolated molecular properties and the performance of these methods in the description of structures, energetics and molecular properties has received considerable attention in recent times [4-9]. In this paper, we used Quantum chemical calculations based on Density Functional Theory (DFT) for structural and electronic characterization of these organometallic complexes, this is due to the fact that, the method has been the most accepted framework to develop and generalize a chemical reactivity theory [10-12]. The calculated properties for the stable structures include dipole moment, spectra (vibration and NMR), the HOMO-LUMO energy band gaps, vertical ionization energies and electron affinities. All the calculations were made using the DFT hybrid functional B3LYP with the basis set 6-31G (D). A suitable description of DFT with B3LYP and basis set 6-31G (D) is available in any computational chemistry text book [13-17]. Generally, the DFT results can be credited with a higher confidence in the quantitative respects due to their treatment of correlation effects while, the regular DFT functional face intrinsic problems in the long range [18-22]. Quantum molecular orbital calculations performed in the framework of DFT approach by using the hybrid B3LYP exchange-functional in combination with the Poples group split valence basis set have been shown to provide excellent compromise between accuracy and computational efficiency 
of molecular structures as well as vibrational and NMR spectra of molecules [23-32]. Time-dependent density functional theory (TDDFT) is an important instrument for calculating and elucidating the electronic excited state properties. The theory applies ground state DFT philosophy to time dependent problems by replacing the complicated many-body time-dependent Schrodinger equation by a set of time-dependent single-particle equation whose orbitals yield the same time-dependent density. The commonest timedependent perturbation is a long wavelength electric field, oscillating with frequency. The field is a weak perturbation of the molecule, and a linear response analysis can be performed, from which the optical absorption spectrum of the molecule due to the electronic excitations can be extracted. The linear response TDDFT predicts the transition frequencies/ excitation energies from electronically ground state to electronic excited states and many other properties [33-37].

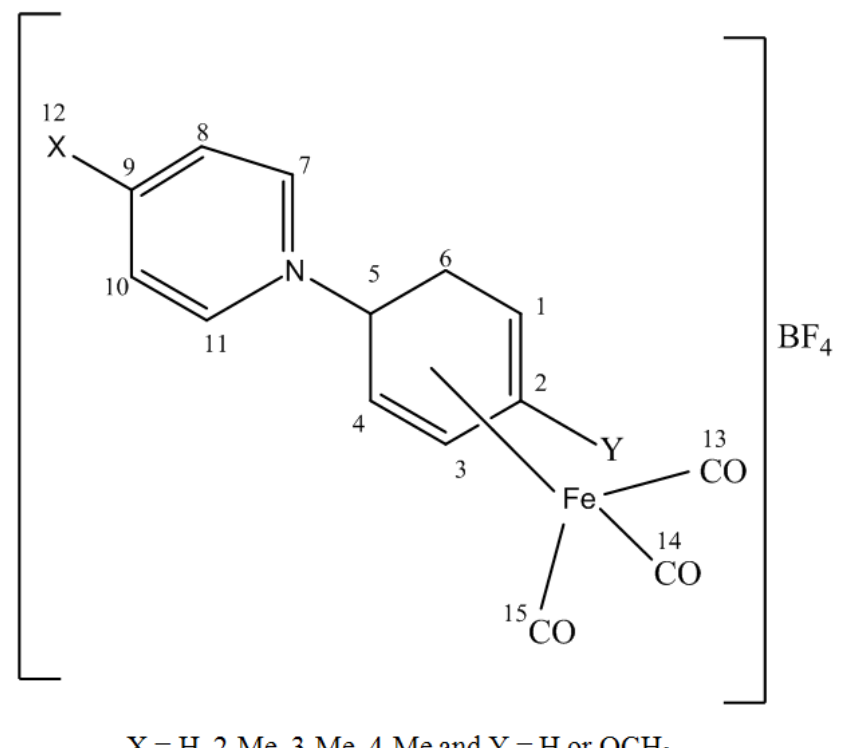

Figure 1. Structure of pyridino-1-4-- $\eta$-cyclohexa-1,3-diene irontricarbonyl.

\section{Computational Method}

All the calculations were performed using Spartan 10 program package using B3LYP methods which uses the exchange functional proposed by Becke and the correlation functional given by Lee, Yang and Parr [23, 24]. The 6-31 (D) basis set has been used in conjunction with DFT method [25]. This basis set has the advantage of being flexible enough to guarantee reliable theoretical results and being small enough for rapid calculations. It represents an excellent compromise between completeness and economy. The molecular geometry was fully optimized without any constraint with the help of analytical gradient procedure implemented within the program A restricted HF-DFT selfconsistent field calculations was carried out using Pulay DIIS and Geometry direct minimization implemented within the program.

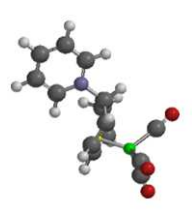

$\mathrm{H}$

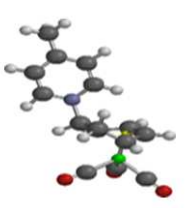

4-Me

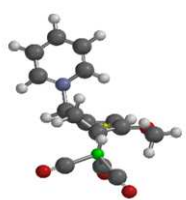

$\mathrm{H}$

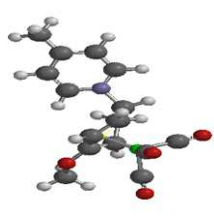

4-Me
Figure 2. Optimized geometries of pyridino-1-4- $\eta$-cyclohexa-1,3-diene irontricarbonyl complexes.

\section{Theoretical Background}

\subsection{Chemical Potential, Hardness and Electronegativity}

In the concept framework of DFT, the chemical potential, $\mu$, is a measure of the escaping tendency of an electron from equilibrium as defined by Parr et al [13]. The electronegativity, $\chi$ could be written as the partial derivative of the system's energy with respect to the number of electrons, $\mathrm{N}$, at the fixed external potential, $v_{(r)}$ :

$$
\mu=\left(\frac{\partial E}{\partial N}\right)_{v_{(r)}}=-\chi
$$

Where $\chi$, is the electronegativity.

The global hardness $\rho$ can be seen as the resistance to charge transfer:

$$
\rho=\frac{1}{2}\left(\frac{\delta^{2} E}{\delta N^{2}}\right)_{v_{(r)}}
$$

According to Mulliken, one has:

$$
\mu=\chi=-\frac{1}{2}(I+A)
$$

And:

$$
\eta=\frac{1}{2}(I-A)
$$

Where $\mathrm{E}$ and $v_{(r)}$ are electronic energy and external potential of an N-electron system,

Using a finite difference approximation and Koopman's theorem 14-17], the above expressions can be written as:

$$
\begin{gathered}
\mu \approx-\frac{1}{2}(I+A) \approx \frac{1}{2}\left(E_{L}+E_{H}\right) \\
\eta \approx \frac{1}{2}(I-A) \approx \frac{1}{2}\left(E_{L}-E_{H}\right)
\end{gathered}
$$

Parr et al., proposed a new DFT concept called the electrophilicity index, $\omega$, in terms of the above two global activity indices, $\mu$ and $\eta$, (equation 7).

$$
\omega=\frac{\mu^{2}}{2 \eta}=\frac{(I+A)^{2}}{2(I+A)}=\frac{\left(E_{L}+E_{H}\right)^{2}}{2\left(E_{L}+E_{H}\right)}
$$

Where $E_{H}$ and $E_{L}$ are the energies of the highest occupied and the lowest unoccupied molecular orbital, I and A, are first ionization potential and electron affinity respectively.

\subsection{Electrophilicity Index}

This is the relative reactivity of an electrophile. An 
electrophile is attracted to electrons that participated in a chemical reaction by accepting electrons to form bond to a nucleophiles [59-61], and because electrophiles accept electrons $[62,63]$, they are Lewis acids according to the general acid-base theory of Bronsted and Lowry [64,65]. Most electrophiles are positively charged, having an atom which carries a partial positive charge or does not have an octect of electrons. The concept of electrophilicity index was quantitatively introduced by Parr et al., [12], and it is referred to as the stabilization energy when atoms and molecules in their ground states acquire additional electronic charge from the environment.

The electrophilicity index, $\omega$, represents the stabilization energy of the system when it gets saturated by electrons coming from the surrounding: The above formulae are working tools for us to calculate the chemical potential, hardness, and electrophilicity index. All the calculated reactivity parameters are based on the values of the chemical potential, $\mu$, and the global chemical hardness, $\eta$. They were calculated using finite difference and the frozen orbital approximations, which yields them in terms of the highest occupied molecular orbital energy, $\mathrm{E}_{\mathrm{H}}$, and the lowest unoccupied molecular orbital energy, $\mathrm{E}_{\mathrm{L}}$.

\section{Results and Discussion}

\subsection{Electronic States}

The HOMO and LUMO of these new organometallic compounds are being visualized because the relative ordering of occupied and virtual orbital provide a reasonable qualitative indication of both ground and excited state properties. The HOMO of these complexes possess a $\pi$ bonding character within the subunit and $\pi$-antibonding character excited state properties between the consecutive subunits. On the other hand, the LUMO possesses a $\pi$ antibonding character within the subunit and a $\pi$-bonding character between the subunits, In practice, the HOMO and LUMO energies are obtained from an empirical formula based on the onset of oxidation-reduction of peaks measured by cyclic voltametry. Theoretically, the HOMO and LUMO energies are calculated using DFT B3LYP (6-31G (D)). These calculations however, do not have solid-state packing effect and aqeuous state is not taken into consideration.

The HOMO is concentrated on all over the metal and cyclohexa-1,3-diene while the LUMO densities are on methylpyridino moiety, thus giving an insight into the reactivity of these complexes and that the movement of electron is from the metal and the cyclohexa-1,3-diene ring towards the methylpyridine ring. The HOMO and LUMO energies together with calculated energy band gap are collected in shown in Table 1. The orbital energy diagram and the HOMO and LUMO energy diagrams are shown in Figure 3.

Table 1. Electronic properties of pyridino-1-4- $\eta$-cyclohexa-1,3-diene irontricarbonyl complexes.

\begin{tabular}{llllllll}
\hline $\mathbf{Y}$ & $\mathbf{X}$ & Total energy/a. u & Dipole moment/D & $\mathbf{E}_{\mathbf{H O M O}} / \mathbf{e V}$ & $\mathbf{E}_{\mathbf{L U M o}} / \mathbf{e V}$ & $\mathbf{E}_{\mathbf{L}}-\mathbf{E}_{\mathbf{H}}=\mathbf{E g} / \mathbf{e V}$ & $\mathbf{P o l a r i z a b i l i t y}$ \\
\hline \multirow{4}{*}{$\mathrm{H}$} & $\mathrm{H}$ & -2084.56 & 12.21 & -9.60 & -6.14 & 3.46 & 62.12 \\
& $2-\mathrm{Me}$ & -2123.90 & 11.38 & -9.56 & -5.92 & 3.64 & 63.49 \\
& $3-\mathrm{Me}$ & -2123.90 & 11.74 & -9.52 & -5.96 & 3.56 & 63.58 \\
& $4-\mathrm{Me}$ & -2123.90 & 12.03 & -9.49 & -5.87 & 3.62 & 63.57 \\
$\mathrm{OCH}_{3}$ & $\mathrm{H}$ & -2199.09 & 12.48 & -9.33 & -6.06 & 3.27 & 64.39 \\
& $2-\mathrm{Me}$ & -2138.41 & 11.73 & -9.28 & -5.83 & 3.45 & 65.75 \\
& $3-\mathrm{Me}$ & -2138.31 & 12.11 & -9.24 & -5.90 & 3.34 & 65.85 \\
& $4-\mathrm{Me}$ & -2138.41 & 12.37 & -9.23 & -5.79 & 3.44 & 65.82 \\
\hline
\end{tabular}

\subsection{Reactivity Parameters}

The calculated reactivity parameters are based on the values of the chemical potential, $\mu$, and the global chemical hardness, $\eta$. They were calculated using finite difference and the frozen orbital approximations, which yields them in terms of the highest occupied molecular orbital energy, $\mathrm{E}_{\mathrm{H}}$, and the lowest unoccupied molecular orbital energy, $\mathrm{E}_{\mathrm{L}}$. The validity of the Koopman's theorem within the DFT approximation is still controversial. However, it has been shown that, the Kohn Sham orbitals may differ in shape and energy from the
Hartree-Fock orbitals. The combination of the two produces conceptual DFT reactivity descriptors that correlate quite well with the reactivity descriptors obtained through HartreeFock calculations. The SCF model used in our calculations is a restricted hybrid HF-DFT-SCF calculations using Pulay DIIS + Geometric Direct Minimization. The combination of the two theories produces result which further revalidates Koopman's theorem. The values of electrophilicity index for these complexes revealed that they are capable of reacting with nucleophiles to give new products. The calculated quantities are listed in Table 2.

Table 2. Reactivity parameters pyridino and methylpyridino-1-4-- $\eta$-cyclohexa-1,3-diene irontricarbonyl complexes.

\begin{tabular}{|c|c|c|c|c|c|c|}
\hline Substituent Y & $\mathbf{X}$ & $\mathrm{I} / \mathrm{eV}$ & $\mathrm{A} / \mathrm{eV}$ & $\mu$ & $\eta$ & $\omega$ \\
\hline \multirow[t]{3}{*}{ - } & $\mathrm{H}$ & 9.60 & 6.14 & -7.87 & 1.73 & 17.90 \\
\hline & 2-Me & 9.56 & 5.92 & -7.74 & 1.82 & 16.37 \\
\hline & 3-Me & 9.52 & 5.96 & -7.74 & 1.78 & 16.83 \\
\hline \multirow{4}{*}{$\mathrm{OCH}_{3}$} & $\mathrm{H}$ & 9.33 & 6.06 & -7.70 & 1.64 & 18.08 \\
\hline & 2-Me & 9.28 & 5.83 & -7.56 & 1.73 & 16.56 \\
\hline & 3-Me & 9.24 & 5.90 & -7.57 & 1.67 & 17.16 \\
\hline & $4-\mathrm{Me}$ & 9.23 & 5.79 & -7.51 & 1.72 & 16.40 \\
\hline
\end{tabular}



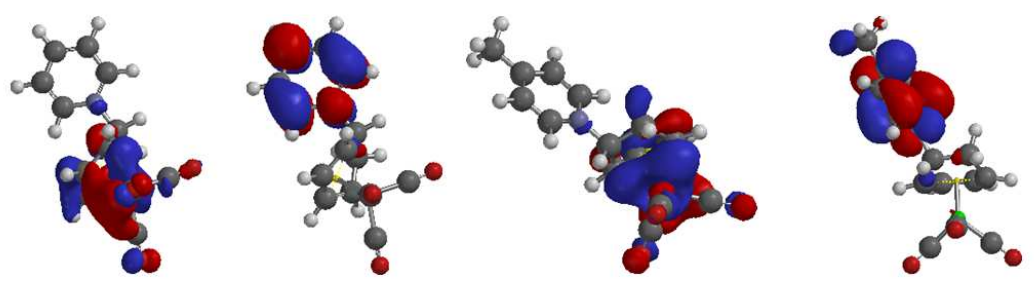

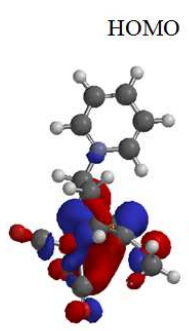

HOMO

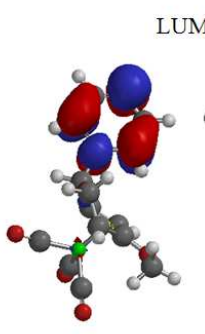

LUMO

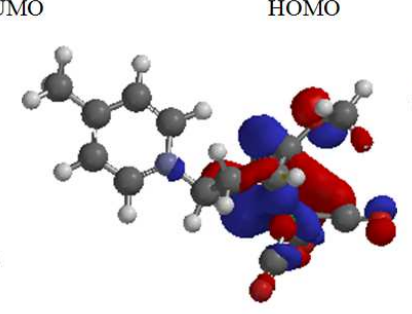

HOMO

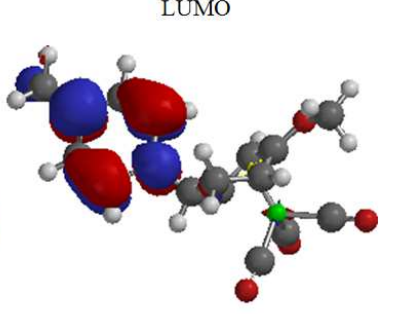

LUMO

Figure 3. HOMO-LUMO energy diagram of pyridino-1-4- $\eta$-cyclohexa-1,3-diene irontricarbonyl complexes.

\subsection{NMR Spectra}

The ${ }^{1} \mathrm{H},{ }^{13} \mathrm{C}$ and ${ }^{15} \mathrm{~N}$ NMR spectra of these complexes were analyzed using Spartan 10 programme software. These complexes show well separated overlapping multiplets characteristics of the outer $\mathrm{H}^{1}$ and $\mathrm{H}^{4}$ and inner $\mathrm{H}^{2}$ and $\mathrm{H}^{3}$ diene protons. The endo $\mathrm{H}^{6}$ and exo $\mathrm{H}^{6}$ protons appeared as shown in the Table 3 and displayed in Figure 4 and figure 5. The $\mathrm{H}^{5}$ proton adjacent to the $\mathrm{N}$-methylpyridino substituent

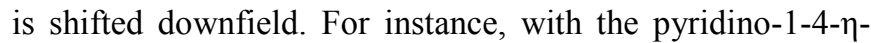
cyclohexa-1,3-diene complex, the Aromatic protons of the pyridine group appear as triplets and doublets while the methylene protons appeared as singlet between $2.18-2.90$ $\mathrm{ppm}$. These values are characteristic features of the 1,3-diene derivatives [69-72]. The ${ }^{13} \mathrm{C}$ chemical shifts calculated at the DFT B3LYP levels of theory with 6-31G (D) basis set are presented in Table 3 while the spectra are shown in Figure 4 and Figure 5. The $\mathrm{C}_{1}, \mathrm{C}_{4}$ and $\mathrm{C}_{6}$ atoms appeared at 47.65 , 50.83 and $37.23 \mathrm{ppm}$, while the chemical shifts of $\mathrm{C}_{2}, \mathrm{C}_{3}$ and $\mathrm{C}_{5}$ appeared at 85.91, 80.80 and $79.08 \mathrm{ppm}$ respectively. All the Aromatic carbons of the pyridine $\mathrm{C}_{7}-\mathrm{C}_{11}$ appeared at $120-157.20 \mathrm{ppm}$ while Carbonyl carbon due to the presence of oxygen and iron are deshielded and consequently have higher chemical shifts at 208-216 ppm. However, the methylene carbon appeared in the range 19-23 ppm. There are no experimental values for ${ }^{13} \mathrm{C}$ but ${ }^{1} \mathrm{H}$ NMR values agrees with available experimental values [69-72]. The aromatic carbon to which the methylene carbon is attached is shifted downfield due to the electron releasing ability of the methyl substituent. Its methoxy analogue presents similar results for all the protons but ${ }^{13} \mathrm{C}$ NMR displayed a radical departure due to the influence of the oxygen attached to carbon 2 . The $\mathrm{C}_{1}, \mathrm{C}_{4}$ and $\mathrm{C}_{6}$ appeared 139.23 , this is attributed to the presence of methoxy group is attached to carbon 2 of the cyclohexa-1,3-diene ring. $47.65,50.83$ and 37.23 while the chemical shifts of $\mathrm{C}_{2}, \mathrm{C}_{3}, \mathrm{C}_{4}$ and $\mathrm{C}_{5}$ appeared at $63.83,37.88$, 42.64 and $79.04 \mathrm{ppm}$. The ${ }^{1} \mathrm{H}$ and ${ }^{13} \mathrm{C}$ NMR spectra data are shown in Table 3 while the spectra are displayed in Figure 4 and Figure 5.

Table 3. NMR Spectra data of pyridino and methylpyridino-1-4- $\eta-2-m e t h o x y c y c l o h e x a-1,3-$ diene irontricarbonyl complexes.

\begin{tabular}{|c|c|c|c|c|c|}
\hline Substituent Y & Proton/Carbon & $\mathbf{H}$ & 2-Me & 3-Me & 4-Me \\
\hline \multirow{16}{*}{$\mathrm{H}$} & $\mathrm{H}_{1}$ & 2.71 & 2.59 & 2.57 & 2.68 \\
\hline & $\mathrm{H}_{2}$ & 5.80 & 5.78 & 5.79 & 5.76 \\
\hline & $\mathrm{H}_{3}$ & 5.57 & 5.70 & 5.65 & 5.55 \\
\hline & $\mathrm{H}_{4}$ & 2.35 & 2.20 & 2.28 & 2.32 \\
\hline & $\mathrm{H}_{5}$ & 4.80 & 5.16 & 4.85 & 4.70 \\
\hline & $\mathrm{H}_{6}$ endo & 2.97 & 2.70 & 2.75 & 2.95 \\
\hline & $\mathrm{H}_{6 \text { exo }}$ & 1.74 & 1.32 & 1.51 & 1.70 \\
\hline & $\mathrm{H}_{8}$ & 7.81 & 7.62 & - & 7.51 \\
\hline & $\mathrm{H}_{9}$ & 8.39 & 8.20 & 8.21 & - \\
\hline & $\mathrm{H}_{10}$ & 7.93 & 7.75 & 7.82 & 7.63 \\
\hline & $\mathrm{H}_{11}$ & 8.61 & 8.68 & 8.41 & 8.30 \\
\hline & $\mathrm{CH}_{3}$ & - & $2.52-2.90$ & $2.18-2.81$ & $2.58-2.87$ \\
\hline & $\mathrm{C}_{1}$ & 47.65 & 45.85 & 46.22 & 47.80 \\
\hline & $\mathrm{C}_{2}$ & 85.91 & 85.63 & 85.71 & 85.55 \\
\hline & $\mathrm{C}_{5}$ & 79.08 & 71.05 & 78.22 & 77.30 \\
\hline & $\mathrm{C}_{6}$ & 37.23 & 32.92 & 36.08 & 37.07 \\
\hline
\end{tabular}


45 Olawale Folorunso Akinyele et al: : Structural and DFT Studies on Molecular Structure of Pyridino-1-4- $\eta$-cyclohexa-1,3-diene and 2-Methoxycyclohexa-1,3-diene Irontricarbonyl Complexes

\begin{tabular}{|c|c|c|c|c|c|}
\hline Substituent Y & Proton/Carbon & $\mathbf{H}$ & 2-Me & 3-Me & 4-Me \\
\hline \multirow{30}{*}{$\mathrm{OCH}_{3}$} & ${ }_{1} \mathrm{H}$ & 2.84 & 2.76 & 2.83 & 2.81 \\
\hline & ${ }_{2} \mathrm{H}$ & - & - & - & - \\
\hline & ${ }_{3} \mathrm{H}$ & 5.16 & 5.34 & 5.17 & 5.15 \\
\hline & ${ }_{4} \mathrm{H}$ & 2.08 & 1.92 & 2.05 & 2.04 \\
\hline & ${ }_{5} \mathrm{H}$ & 4.56 & 4.88 & 4.49 & 4.47 \\
\hline & ${ }_{6} \mathrm{H}$ & 2.93 & 2.73 & 2.88 & 2.84 \\
\hline & ${ }_{6} \cdot \mathrm{H}$ & 1.68 & 1.33 & 1.65 & 1.62 \\
\hline & $\mathrm{OCH}_{3}$ & $3.55-4.10$ & $3.51-4.06$ & $3.54-4.09$ & $3.54-4.08$ \\
\hline & ${ }_{8} \mathrm{H}$ & 8.09 & - & 7.79 & 7.86 \\
\hline & ${ }_{9} \mathrm{H}$ & 7.78 & 7.58 & - & 7.48 \\
\hline & ${ }_{10} \mathrm{H}$ & 8.47 & 8.16 & 8.18 & - \\
\hline & ${ }_{11} \mathrm{H}$ & 7.90 & 7.73 & 7.78 & 7.62 \\
\hline & ${ }_{12} \mathrm{H}$ & 8.57 & 8.85 & 8.33 & 8.35 \\
\hline & $\mathrm{CH}_{3}$ & - & $2.46-2.84$ & $2.13-2.79$ & $2.57-2.86$ \\
\hline & $\mathrm{C}_{1}$ & 139.23 & 139.51 & 139.21 & 139.13 \\
\hline & $\mathrm{C}_{2}$ & 63.87 & 64.44 & 64.19 & 64.06 \\
\hline & $\mathrm{C}_{3}$ & 37.88 & 36.94 & 38.00 & 37.82 \\
\hline & $\mathrm{C}_{4}$ & 42.64 & 39.31 & 42.48 & 42.23 \\
\hline & $\mathrm{C}_{5}$ & 79.04 & 71.33 & 78.40 & 77.54 \\
\hline & $\mathrm{C}_{6}$ & 38.59 & 34.21 & 38.16 & 37.98 \\
\hline & $\mathrm{C}_{7}$ & 136.19 & 148.85 & 135.79 & 135.15 \\
\hline & $\mathrm{C}_{8}$ & 122.19 & 124.43 & 137.03 & 122.57 \\
\hline & $\mathrm{C}_{9}$ & 139.35 & 138.48 & 140.01 & 156.80 \\
\hline & $\mathrm{C}_{10}$ & 123.03 & 120.18 & 122.13 & 123.64 \\
\hline & $\mathrm{C}_{11}$ & 133.99 & 134.52 & 131.11 & 132.59 \\
\hline & $\mathrm{OCH}_{3}$ & 54.08 & 54.07 & 53.99 & 54.00 \\
\hline & $\mathrm{C}_{13}$ & 214.46 & 214.93 & 214.80 & 214.52 \\
\hline & $\mathrm{C}_{14}$ & 206.90 & 206.99 & 207.11 & 206.99 \\
\hline & $\mathrm{C}_{15}$ & 209.60 & 209.80 & 209.81 & 209.81 \\
\hline & $\mathrm{C}_{16}$ & - & 20.26 & 18.91 & 22.30 \\
\hline
\end{tabular}
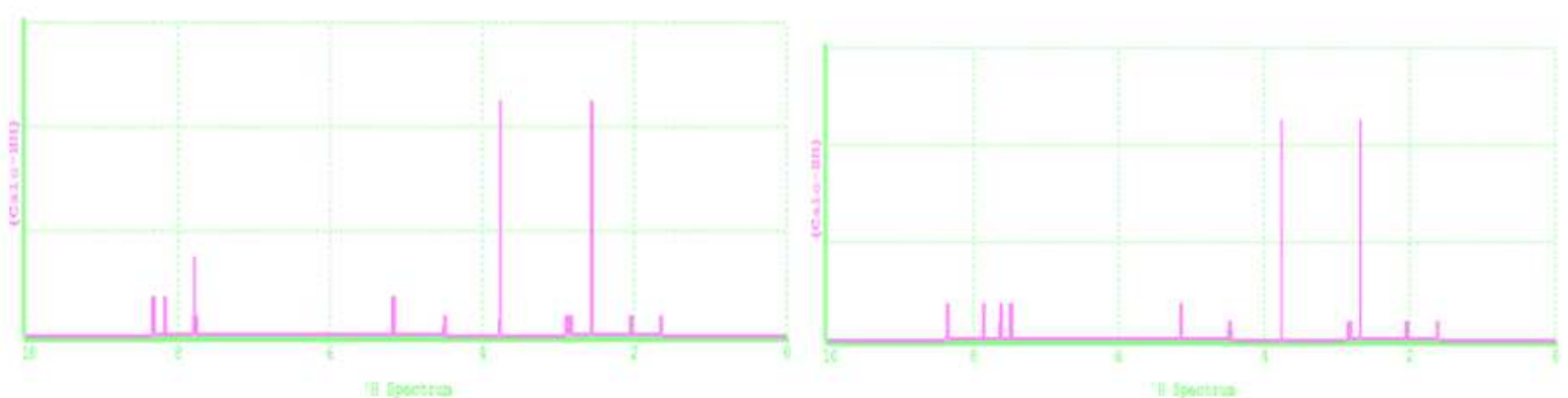

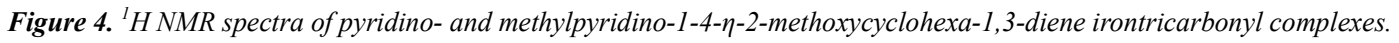



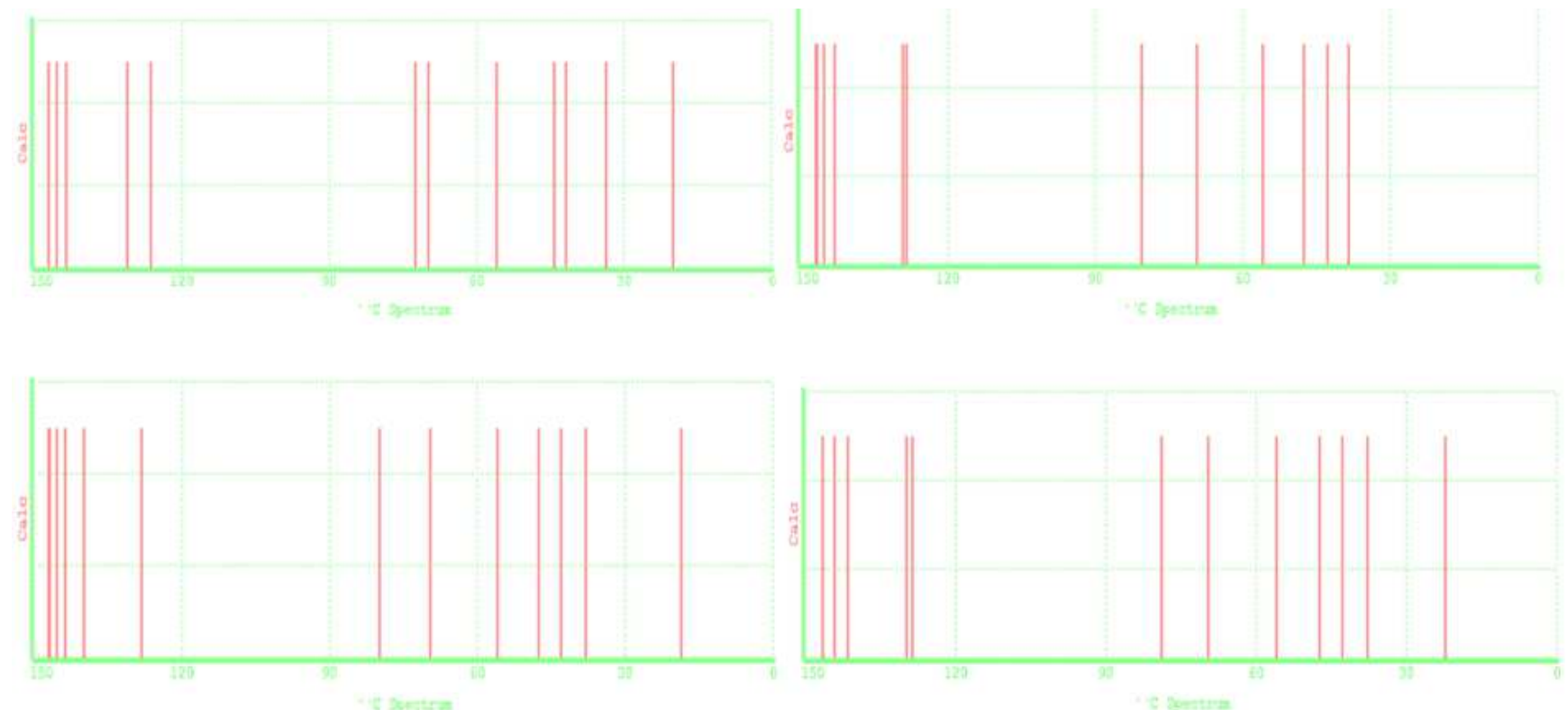

Figure $5 .{ }^{13}$ C NMR spectra of pyridino- and methylpyridino-1-4- $\eta$-cyclohexa-1,3-diene irontricarbonyl complexes.

\subsection{Vibrational Analysis}

There are 87 and 96 A normal modes of vibration for the pyridino- and the methylpyridino-1-4- $\eta$-cyclohexa-1, 3-diene irontricarbonyl complexes while its methoxy analogue presents 99 and 108 normal vibrations. We present the calculated vibrational frequencies from gas phase infra-red spectra (Figure 6) of the complexes without any scale factor. The absence of any imaginary frequency indicates that all the optimized structures correspond to the minimum point on the intramolecular potential energy surface. Analysis of the calculated vibrational frequencies of the complexes shows no large deviation. The complexes have very sharp and strong peak at $2108-2165 \mathrm{~cm}^{-1}$ corresponding to the stretching vibrations of the $\mathrm{C} \equiv \mathrm{O}$ bond. It is clearly seen that these groups have corresponding IR signatures which are expected to provide useful information for further studies. Our theoretical vibrational frequencies agree with the experimental values [69-74].
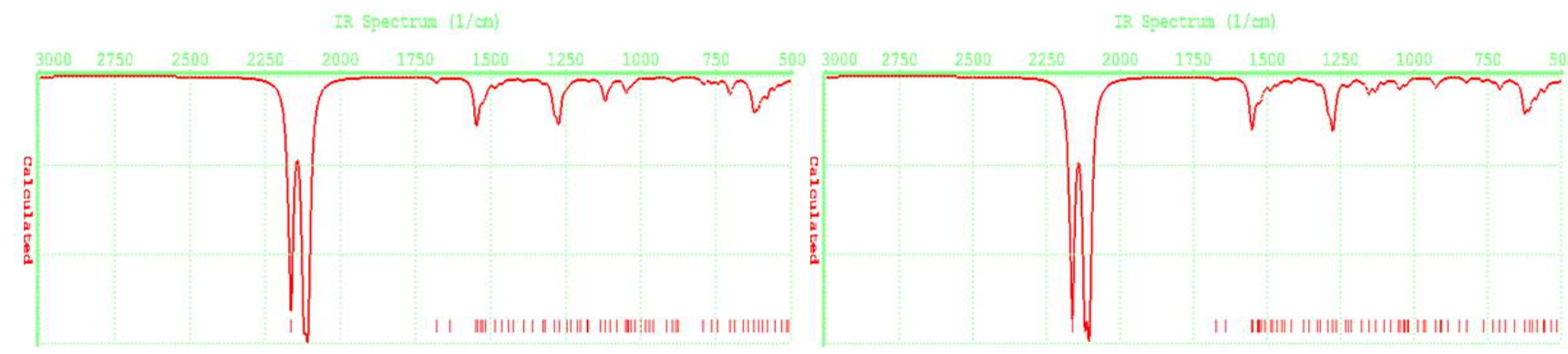

Figure 6. Infra-red spectra of pyridino-1-4- $\eta$-cyclohexa-1,3-diene irontricarbonyl.

\subsection{Electronic Transitions and UV/Vis Spectra}

The Uv-visible absorption spectra of the complexes in the gas phase were calculated using TDDFT, the spectra are shown in Figure 6. There is charge transfer from the irontricarbonyl cyclohexa-1,3-diene ring to the substituted pyridine ring in the excitation process. The absorption bands in the visible region are assigned to the MLCT transitions in which an electron is promoted from molecular orbital belonging to the filled metal shell to the empty $\pi^{*}$ orbital of the substituted pyridine. All the organometallics possess similar spectra features in which the two lower-lying bands that appear in the region 413.94 and $364.44 \mathrm{~nm}$ as supported by their oscillator strength 0.0187 are assigned to the ${ }^{1}$ MLCT and ${ }^{3}$ MLCT transitions. The oscillator strength of these two bands are the same which suggests that the transition from ground state $\mathrm{S}_{0}$ to ${ }^{3} \mathrm{MLCT}$ transition is enhanced and become partially allowed due to strong spin-orbit coupling and similar molecular geometry in the excited state singlet and triplet states [75-77]. 


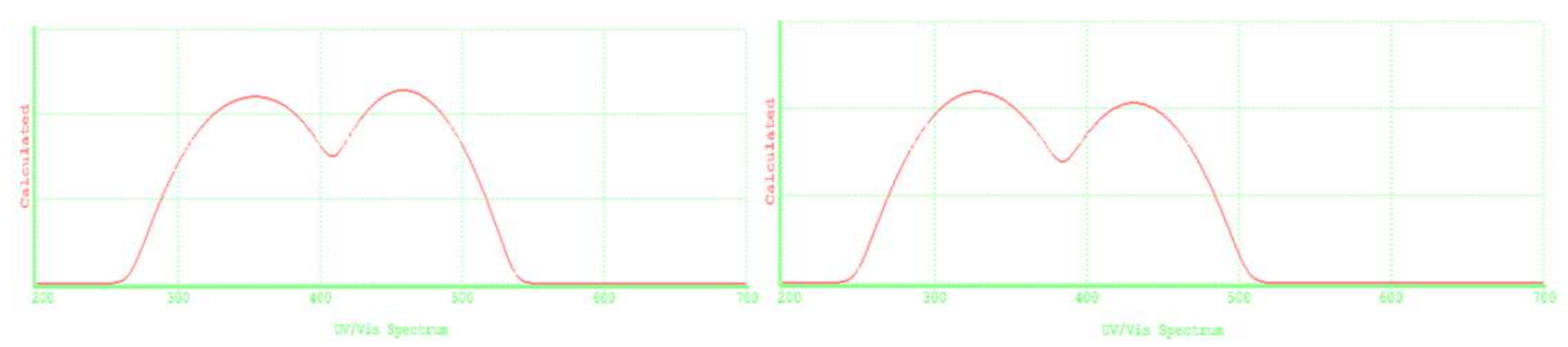

Figure 7. UV-visible spectra of pyridino-1-4- $\eta$-cyclohexa-1, 3-diene irontricarbonyl.

\section{Conclusion}

We have calculated the structure of the novel compound pyridino-1-4- $\eta$-cyclohexa-1,3-diene irontricarbonyl using DFT B3LYP with basis set 6-31G(D). Theoretical characterization molecular calculations were carried out on optimized geometries. These calculations include Uv-Visible, Infra-red and NMR. The calculated infra-red and ${ }^{1} \mathrm{H}$ NMR values agrees with experimental values. We studied the electronic states of these complexes as a function of reactivity parameters. Since the SCF model used in our calculations is a restricted hybrid HF-DFT SCF calculations performed using Pulay DIIS + Geometric Direct Minimization the combination of the two theories produces a result which further validates Koopman's theorem for these complexes. The reactivity indices for these complexes revealed that they are capable of reacting with electron rich compounds to give new products.

The excited state of these complexes is a mixture of singlet and triplet hence the relaxation from the excited state singlet $\left(\mathrm{S}_{1} \rightarrow \mathrm{S}_{0}\right)$ gives fluorescence while the relaxation from the excited state triplet to ground state singlet $\left(\mathrm{T}_{1} \rightarrow \mathrm{S}_{0}\right)$ results to phosphorescence.

\section{References}

[1] A. P. Farhan, K. S. Hemant, B. Yakoob, P. S. Pashupati. DFT based electrophilicity index and QSAR study of phenols as anti leukaemia agent, American Journal of Immunology, 2006, 2 (1): 23-28.

[2] W. Kohn, A. D. Becke, R. G. Parr. Density functional theory of electronic structure, J. of Phys. Chem. 1996, 100, 1297412980.

[3] P. Hohenberg, W. Kohn. Original papers: Physical Review B, 1964, 136: 864-887.

[4] R. G. Parr, R. Domnelly, M. Levy, W. Palke. Electronegativity: The density functional view point. Journal of Chemical Physics. 1978, 68: 3801-3805.

[5] P. Geerlings, F. De Proft, W. Langenaeker, Density functional theory: A source of chemical concept and cost-effective methodology for their calculations. Advances in Quantum Chemistry, 1996, 33, 303-329.

[6] F. De Proft, J. L. Martin, P. Geerlings. Calculation of molecular electrostatic potentials and fukui functions using density functional. Chemical Physics Letters, 1996, 256: 400-408.
[7] F. De Proft, J. L. Martin, P. Geerlings. On the performance of density functional methods for describing atomic populations, dipole moments and infrared intensities. Chem. Phys. Let. 1996, 256, 393-401.

[8] P. K. Chattaraj, A. Cedillo, R. G. Parr. Variational method for determining the Fukui- function and chemical hardness of an electronic system. J. Phys. Chem. 1995, 103, 7645-7646.

[9] P. W. Ayers, R. G. Parr, Variational Principles for Describing Chemical Reactions: The Fukui Function and Chemical Hardness Revisited, J. Am. Chem. Soc. 2000, 122, 2010 2018.

[10] G. Korth, M. I. De Hear, P. A. Mulde. DFT Study on Intramolecular Hydrogen Bonding in 2-Substituted Phenols: Conformations, Enthalpies, and Correlation with Solute Parameters. J. Phys. Chem. A. 2002, 106, 8779-8789.

[11] R. G. Parr, R. Pearson. Absolute hardness: companion parameter to absolute electronegativity. J. Am. Soc. 1983, 105, $7512-7516$.

[12] R. G. Parr, L. Von Szentpaly, S. Liu. Electrophilicity index. Journal of American Chemical Society 1999, 121: 1922-1924.

[13] R. G. Parr, W. Yang. Density Functional theory of atoms and molecules. NY, Oxford University press, 1989.

[14] C. J. Cramer. Essentials of Computational ChemistryTheories and models. Chichester, John-Wiley \& Sons, 2002.

[15] D. Young. A practical guide for applying techniques to Real world problems. New York, John-Wiley \&Sons, 2001.

[16] E. Lewars. Computational Chemistry- Introduction to the theory and applications of Molecular and Quantum mechanics. Norwell, MA. Kluwer Academic Publishers, 2003.

[17] F. Jensen. Introduction to Computational Chemistry. Chichester, John-Wiley \& Sons, 2007.

[18] A. E. Reed, L. A. Curtiss, F. Weinhold. Intermolecular interactions from a natural bond orbital, donor-acceptor viewpoint. Chem. Rev. 1988, 88, 899-926.

[19] P. Fuentealla, J. David, D. Guerra. Density functional based reactivity parameters: Thermodynamic or kinetic concepts? J of Mol. Struct. THEOCHEM. 2010, 943. 127-137.

[20] X. J. Li, G. S. Jiao. Theoretical studies of the functionalized derivatives of fullerene $\mathrm{C}_{24} \mathrm{H}_{24}$ by attaching a variety of chemical groups. J. of Mol. Struct. THEOCHEM. 2009, 893. 26-30.

[21] G. Maroulis, D. Xenides. Electric Multipole Moments and (Hyper) Polarizability of $\mathrm{X}-\mathrm{C} \equiv \mathrm{C}-\mathrm{X}, \mathrm{X}=\mathrm{F}, \mathrm{Cl}, \mathrm{Br}$ and I. Int. J. Mol. Sci. 2003, 4, 263-271. 
[22] V. Chis, A. Pirnau, M. Vasilescu, R. A. Varga, O. Oniga. Xray, $1 \mathrm{H}$ NMR and DFT study on 5-para-X-benzylidenethiazolidine derivatives with $\mathrm{X}=\mathrm{Br}$, F. J of Mol. Struct. THEOCHEM. 2008, 851. 63-74.

[23] A. D. Becke. "A new mixing of Hartree-Fock and local density-functional theories". Journal of Chemical Physics 1993, 98, 1372-1377.

[24] C. Lee, W. Yang, R. G. Parr. Development of the ColleSalvetti correlation-energy formula into a functional of electron density. Physical Review B. 1988, 37: 785-789.

[25] W. J. Hehre, L. Radon, P. R. Schleyer. J. A. Pople. Ab initio Molecular Orbital Theory. New York, 1986.

[26] L. Szabo, V. Chis, A. Pirnau, N. Leopold, O. Cozar, S. Orosz. Spectroscopic and theoretical study of amlodipine besylate, J. of Mol. Struct. 2009, 926, 385-392.

[27] M. Szafran, J. Koput, Z. Dega-Szafran. B3LYP study of the conformers and rotamers of isostructural N-methylpiperidine betaine hydrochloride and (1methylcyclohexyl)-acetic acid. The effect of electrostatic attraction on rotation barriers" J. Mol. Struct, 2005, 749, 114-121.

[28] J. C. Dobowalski, J. E. Rode, J. Sadlej. Cysteine conformations revisited. J. of Mol. Struct. THEOCHEM. 2007, 810, 129-134.

[29] K. Laihia, A. Puszko, J. Linnanto, E. Kolehmainen, ${ }^{1} \mathrm{H},{ }^{13} \mathrm{C}$ and ${ }^{15} \mathrm{~N}$ NMR spectral and theoretical studies of some methyl and alkylamino derivatives of 4-halopyridine N-oxides', J. Mol. Struct. 2006, 783 73-78.

[30] J. Linnanto, J. E. I. Korppi-Tommola, 'Spectroscopic properties of Mg-chlorin, Mg-porphin and chlorophylls a, b, c1, c2, c3 and d studied by semiempirical MO/CI methods', Phys. Chem. Chem. Phys., 2000, 2, 4962-4970.

[31] J. Zhang, H. Zheng, T. Zhang, M. Wu. Theoretical Study for High-Energy-Density Compounds Derived from cyclophosphazene. IV. DFT Studies on 1,1-Diamino3,3,5,5,7,7-hexaazidocyclotetraphosphazene and Its Isomers, Int. J. Mol. Sci. 2009, 10, 3502-3516.

[32] P. W. Ayers, J. S. M. Anderson, L. J. Bartolotti. Perturbative perspectives on the chemical reaction prediction problem. Int. J. Quantum Chem. 2005, 10. 520-534.

[33] R. E. Stratmann, G. E. Scuseria, M. J. Frisch. An efficient implementation of Time-dependent density functional theory for the calculation of excitation energies of large molecules, J. Chem. Phys. 1998, 109, 8218-8224.

[34] M. E. Casida, C. Jamorski, K. L. Casida, D. R. Salahub. Molecular excitation energies to high-characterization and correction of the Time-dependent local density approximation ionization threshold, J. Chem. Phys. 1998, 108, 4439-4450.

[35] G. Dominique, N. Shinichiro. Calculation of the absorption wavelength of dyes using time-dependent density functional theory (TD-DFT), Dyes and Pigments 2000, 46, 85-92.

[36] S. H. Brewer, D. Wicaksana, M. Jon-Paul. Investigation of the electrical and optical properties of iridium oxide by reflectance FTIR spectroscopy and density functional theory calculations. Chem. Phys. 2005, 313, 25-31.

[37] L. E. Forslund, F. Rudiger, N. Kaltsoyannis. Time-dependent density functional theory studies of the electronic absorption spectra of N, N-disubstituted 2, 3-dialkylnyl-1,4-diazabuta1,3-dienes, J. Chem. Soc., Perkin Trans, 2002, 2, 494-501.

[38] J. Ren, E. Kaxiras, S. Meng. Optical properties of clusters and molecules from real-time time-dependent density functional theory using a self-consistent field, Mol. Phys. 2010, 108 (14), 1829-1844.

[39] G. F. Bertsch, A. Schnell, K. Yabana. Electron-vibration coupling in time-dependent density functional theory: Application to benzene. J. Chem. Phys. 2001, 115, 4051-4060.

[40] Z. Liu. Theoretical studies of natural pigments relevant to sensitized solar cells. J. Mol. Struct. Theochem. 2008, 862, 44-48.

[41] D. Glossman-Mitnik. Computational molecular characterisation of coumarin-102. J. Mol. Struct. Theochem. 2009, 911, 105-108.

[42] C. Morell, A. Grand, A. Toro-Labe. A new dual descriptor for chemical reactivity, J. Phys. Chem. A. 2005, 109, 205-212.

[43] S. Shigeyoshi, O. Yu-ya, S. Hirofumi. Theoretical and computational studies of organometallics reactions: Successful or not? The. Chem. Rec. 2010, 10, 29-45.

[44] C. J. Cramer, D. G. Truhlar. Density functional theory for transition metal and transition metal chemistry, Phys. Chem. Chem. Phys. 2009, 11, 10757-10816.

[45] M. A. L. Marques, E. K. U. Gross. Time dependent density functional theory, Annu. Rev. Phys. Chem. 2004, 55, 427-455.

[46] R. J. Cave, K. Burke, E. W. Castener Jr. "Theoretical Investigation of the Ground and Excited States of Coumarin 151 and Coumarin 120," J. Phys. Chem. 2002, A, 106, 92949305.

[47] L. Bernasconi, M. Sprik, R. Hutter. Hartree-Fock exchange in time dependent density functional theory: Application to charge transfer excitations in solvated molecular systems, Chem. Phys. Lett. 2004, 394, 141-146.

[48] R. E. Roy, T. Hughbanks. Electronic transition in $\left[\operatorname{Re}_{6} \mathrm{~S}_{8} \mathrm{X}_{6}\right]$, $(\mathrm{X}=\mathrm{Cl}, \mathrm{Br}, \mathrm{I})$ : Results from time-dependent density functional theory and solid-state calculations, Inorg. Chem. 45, 2006, 8273-8282.

[49] N. A. Besley, A. J. Blundy. Electronic excited states of Si (100) and organic molecules adsorbed on Si (100). J. Phys. Chem. B, 2006, 110, 1701-1710.

[50] K. Hirose, Y. Meir, N. S. Wingreen. Time-dependent density functional theory of excitation energies of closed-shell quantum dots. Physica E, 2004, 22, 486-489.

[51] N. T. Maitra, K. Burke, C. Woodward. Memory in timedependent density functional theory, Phys. Rev. Letts. 2002, 89, 023002.(pp1-4).

[52] M. Petersilka, U. J. Gossmann, E. K. U. Gross. Excitation energies from time-dependent functional theory, Phys. Rev. Lett. 76, 1996, 1212-1215.

[53] F. Della Sala, D. Gorling. Excitation energies using an effective exact-exchange Kohn-Sham potential for molecules. Int. J. Quantum. Chem. 2003, 91, 131-138.

[54] T. Grabo, M. Petersilka, E. K. U. Gross. Molecular excitation energies from time dependent density functional theory. J. Mol. Struct. (Theochem), 2000, 501, 353-367. 
[55] H. Appel, E. K. U. Gross, K. Burke. Excitations energies in time-dependent density functional theory. Phys. Rev. Lett. 2003, 90, 043005. (pp1-4).

[56] M. Petersilka, E. K. U. Gross, K. Burke, Excitations energies from time-dependent density functional theory using exact and approximate functionals, Int. J. Quantum Chem. 2000, 80, 534-554.

[57] J. M. Tao, G. Vignale. Time-dependent density functional theory beyond the local-density approximation. Phys. Rev. Lett. 2006, 97, 036403. (pp 1-4).

[58] Spartan 10V1.1.0, Wavefunction Japan, 2010.

[59] M. Elango, R. Parthasarathi, G. N. Karthik, A. M. Sabeelullah, U. Sarkar, N. S. Venkatasubramaniyan, V. Subramanian, P. K. Chattaraj, Relationship between electrophilicity index, Hammett constant and nucleus-independent chemical shift $\mathrm{J}$. Chem. Sci. 2005, Vol. 117. No 1. 61-65.

[60] R. Parthasarathi, V. Subramanian, D. R. Roy, P. K. Chattaraj. Electrophilicity index as a possible descriptor of biological activity, Bioorg. and Med. Chem. 2004, 12, 5533 -5544.

[61] D. R. Roy, R. Parthasarathi, B. Maiti, V. Subramanian, P. K. Chattaraj. Electrophilicity as a possible descriptor for toxicity prediction Bioorg. \& Med. Chem. 2005, 13, 3405-3412.

[62] C. K. Ingold. Significance of tautomerism and of the reactions of aromatic compounds in the electronic theory of organic reactions, J. Chem. Soc. 1933, 1120.

[63] C. K. Ingold. Principle of an electronic theory of organic reactions, Chem. Rev. 1934, 15, 225.

[64] J. N. Bronsted. The electronic theory of valency. IV. The origin of acidity. Recl. TraN. Chim. Pays-Bas, 1923, 42, 718.

[65] T. M. Lowry. The Uniqueness of Hydrogen" Chemistry and Industry, 1923, 42, 43-47.

[66] H. Mayr, M. Patz. Scales of nucleophilicity and electrophilicity: A system for ordering polar organic and organometallic reactions. Angew. Chem. Int. Ed. Engl. 1995, 34,3350 .

[67] S. A. Payan-Gomez, N. Flores-Noiguin, A. Perez-Hernandez, M. Pnon-Miramontes, D. Glossman-Mitnik. Computational molecular characterization of the flavonoid Morin and its Pt (II), Pd (II) and Zn (II) complexes. J. of Mol. Mod. 2011, 17, 979-985.
[68] S. M. Smith, A. N. Markevitch, D. A. Romanov, X. Li, R. I. Levis, B. H. Schlegel. Static and Dynamic Polarizabilities of Conjugated Molecules and Their Cations. J, Phys-Chem. A, 2004, 108, 11063-11072.

[69] A. Prrnau, V. Chis, O. Oniga, N. Leopold, L. Szabo, M. Baias, O. Cozar. Vibrational and DFT study of 5-(3-pyridylmethylidene)-thiazolidine-2-thione-4-one. Vibrational Spectroscopy, 2008, 48, 289-296.

[70] J. Weinberg, D. A. Lerner, C. Balaceanu-Stolnici. Theoretical study of DHEAS: the electronic properties of a complex between DHEAS and serotonin by comparative calculations HF and DFT Revue Roumaire de Chimie, 2007, 52 (8-9) 759764.

[71] I. A. Adejoro, T. I. Odiaka, O. F. Akinyele. (2014). Density functional theory and reactivity parameters of dimethylpyridino-1-4- $\eta$-cyclohexa-1,3-diene iron tricarbonyl complexes. Journal of Natural Science Research, 2014, 4 (1): $38-45$.

[72] T. I. Odiaka, J. I. Okogun. Synthetic and mechanistic studies

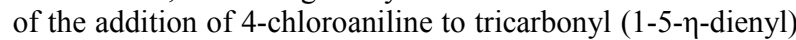
iron II cations J. Organomet. Chem. 1985, 288, C30-32.

[73] T. I. Odiaka. Synthetic and mechanistic studies of the addition

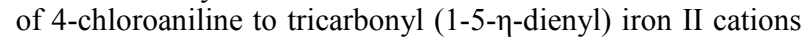
J. Organomet. Chem. 1987, 321, 227-235.

[74] T. I. Odiaka. Synthetic and Mechanistic Studies of the addition of 2,6-dimethylaniline to tricarbonyl (1-5- $\eta$-dienyl) iron (II) complexes. (Dienyl $=\mathrm{C}_{6} \mathrm{H}_{7}, 2-\mathrm{MeOC}_{6} \mathrm{H}_{7}$ or $\mathrm{C}_{7} \mathrm{H}_{9}$ ). Inorganica Chimica Acta, 1988, 145, 267-271.

[75] G. Y. Zheng, D. P. Rillema, J. DePriest, C. Woods. Comparison of solid-state and solution photophysical properties of a platinum (II) biphenyl dicarbonyl Complex: A multiple-state emission study. Inorg Chem. 1998, 37 (14), 3588-3592.

[76] S. Perun, J. Tatchen, C. M. Marian. Singlet and Triplet Excited States and Intersystem Crossing in Free - Base Porphyrin: TDDFT and DFT/MRCI Study ChemPhysChem. 2008, 9, 282-292.

[77] S. Reindl, A. Penzkofer. Higher Excited-State Triplet - Singlet Intersystem Crossing of Some Organic Dyes, Chem. Phys. 1996, 211, 431-439. 